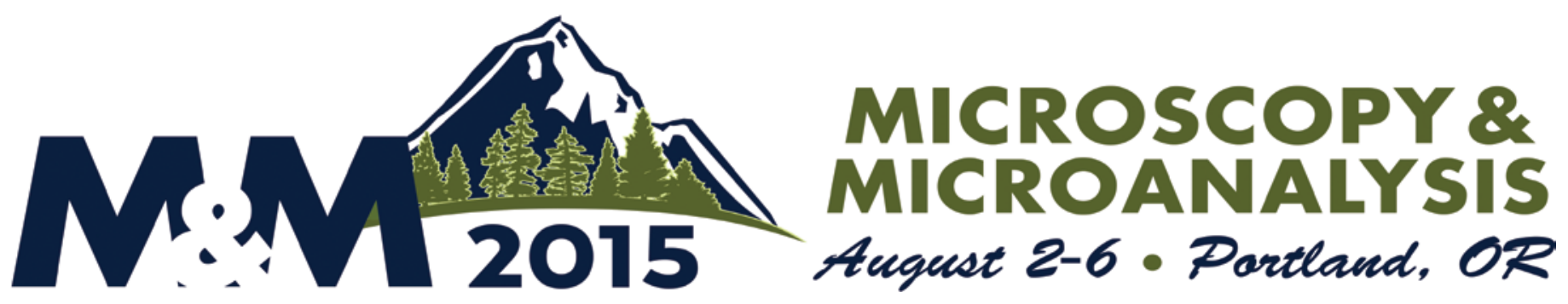

\title{
Microscopy \& Microanalysis 2015 in Portland
}

\author{
Mark A. Sanders, Program Chair \\ University Imaging Centers, University of Minnesota, Minneapolis, MN 55445
}

msanders@umn.edu

The Microscopy Society of America, the Microanalysis Society, and the International Metallographic Society invite you to Microscopy \& Microanalysis 2015 in Portland, Oregon. The "City of Roses" will be the perfect latesummer host for our annual M\&M meeting. Certainly many of you fondly recall our previous visits there in 1999 and 2010.

The overarching M\&M 2015 theme is correlative imaging, with a nod to light-based technologies. The United Nations General Assembly proclaimed 2015 as the "International Year of Light and Light-Based Technologies," which nicely highlights the interdisciplinary symposia that reflect the current environment of collaboration between scientists in different disciplines represented at our annual M\&M meeting.

Once again the latest and most innovative applications and instrumentation developments will be on show using microscopy and microanalysis techniques in the biological and physical sciences. The M\&M 2015 meeting will feature two plenary lectures, $40+$ symposia covering a broad range of topics, numerous educational opportunities in the form of courses and tutorials, pre-meeting events including short courses, and a pre-meeting congress.

We are excited to host Professor Roger Tsien as one of two plenary speakers. He is a member of the National Academy of Sciences and The Royal Society. Dr. Tsien is best known for designing and building molecules that either report or perturb signal transduction inside living cells. These efforts lead to a Nobel Prize in Chemistry (shared with O. Shimomura and $\mathrm{M}$. Chalfie, 2008). During his long and fruitful career, Dr. Tsien received several international awards in recognition of his

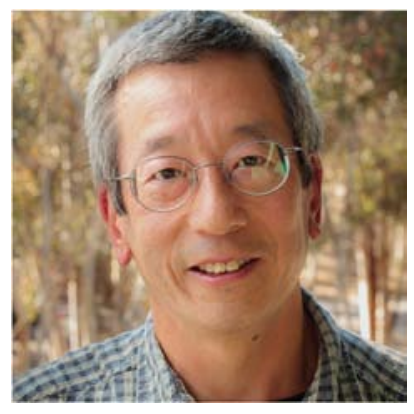
accomplishments; a partial list: Artois-Baillet-Latour Health Prize (1995), Gairdner Foundation International Award (1995), Award for Creative Invention from the American Chemical Society (2002), Heineken Prize in Biochemistry and Biophysics (2002), Wolf Prize in Medicine (shared with Robert Weinberg, 2004), Rosenstiel Award (2006), and the E.B. Wilson Medal of the American Society for Cell Biology (shared with M. Chalfie, 2008). The second plenary speaker will be an astronaut from NASA. We cannot release the name until February, but rest assured the selected speaker will show us that microscopy and microanalysis can lead to amazing out-of-this-world discoveries.

Two symposia will honor the memory of microscopy leaders in the biological and physical sciences. The "Robert P. Apkarian Memorial Symposium on Advances in High Resolution Scanning Electron Microscopy" will recognize the late Dr. Robert P. Apkarian (1953-2006) for his work in the field of biological electron microscopy and his services to MSA and other microscopy societies. The physical sciences memorial symposium "Bringing the real World into the Electron Microscope" will honor Dr. Peter Swann (1935-2013). These will dovetail with several symposia supplementing these topics by investigating the limits, pros and cons, and future of new instruments in multiple research fields, for example, "Advances in Electron and Ion Scanning Microscopies," "Microscopy and Microanalysis for Real World Problem Solving," and "Advanced Analytical TEM/STEM."

Other Instrumentation and Techniques symposia relate to both physical and life sciences. Examples include the following: "Mass Spectrometry Imaging - MALDI," "Fast and Ultrafast Imaging with Electrons and Photons," "Advances in FIB: New Instrumentation and Applications in Materials and Biological Sciences," and "Scanning Probe Microscopy: New Methods and Applications." Data simulations and interpretation will be examined in "Combined Advances in Simulation and Experiment for Materials Characterization and Design." Instrument developers and vendors also will have the opportunity to showcase new developments and improved products in the "Vendor Symposium: Latest Developments in Tools for Life and Materials Sciences." 


\section{Innovation at SPI Supplies}

UV Prep" FOR SEM
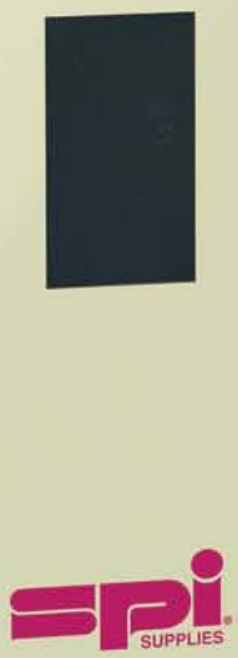

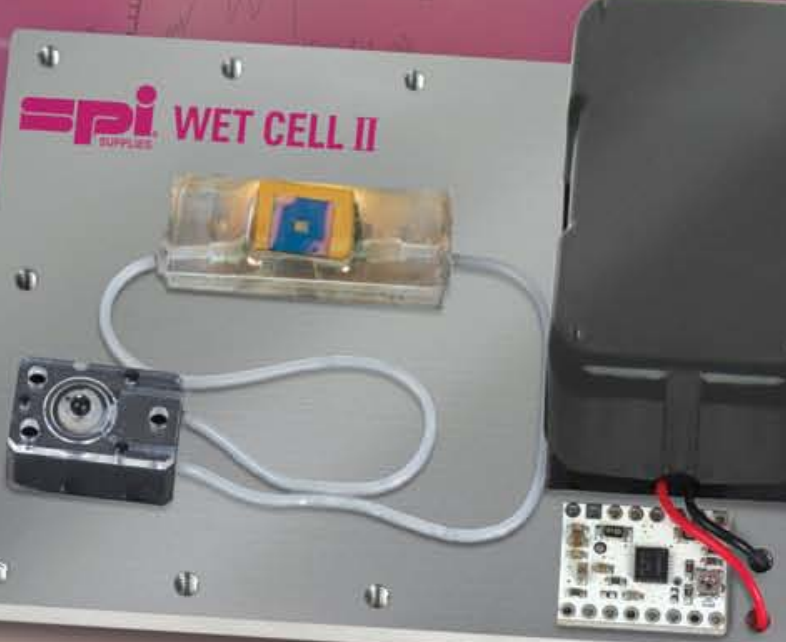

\section{UV Prep for SEM • Wet Cell II}

Get more detail from your SEM samples.

The UV Prep uses a customized UV source to effectively attack and break up hydrocarbon bonds. At the same time, reactive species of oxygen react with these hydrocarbon bonds forming molecules such as $\mathrm{H}_{2} \mathrm{O}, \mathrm{CO}$ and $\mathrm{CO}_{2}$, which are pumped out of the chamber. The result is a surface free of hydrocarbon contamination.

\section{Liquid Probe System for SEM/EDS, EPMA and TOF-SIMS systems.}

The Wet Cell II is the next generation device for the examination of liquids in an EM environment. The self contained high vacuum compatible device enables the analyst to characterize a fluid in its natural state.

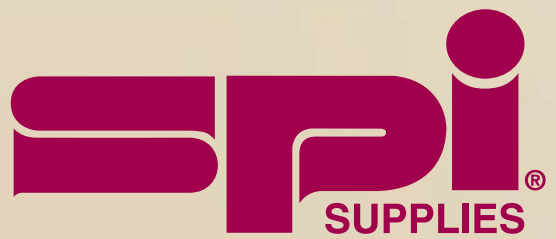

SPI Supplies Division of STRUCTURE PROBE, Inc. 


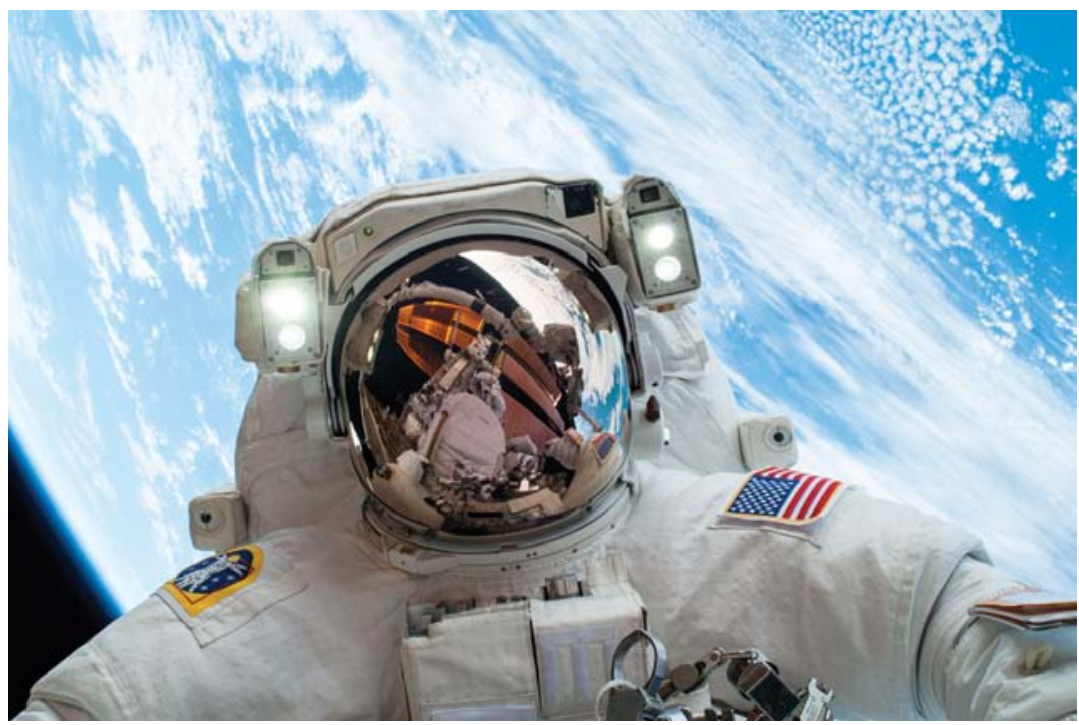

A NASA astronaut will be a plenary speaker. Image courtesy of NASA.

Life science symposia will be devoted to understanding basic concepts in cellular, molecular, and structural biology and will include the following: "3D Structures of Macromolecular Assemblies, Cellular Organelles and Whole Cells," and "Dynamic Fluorescence Microscopy." The symposia "Multiscale Biological Imaging: From Micro- to Macro-animal to Clinical Models" and "Microscopy, Microanalysis, and Image Cytometry in the Pharmaceutical Sciences" present medical and pharmacological aspects. Two novel symposia exploring biological tissues and the role of microscopy and photomanipulation are "Optogenetics: Shining New Light on Neural Circuit Function" and "Deep Tissue Imaging and Light Sheet Microscopy."

Physical science symposia at M\&M 2015 will showcase modern materials and their analysis: "Microscopy of Additive Manufacturing and 3D Printing in Materials and Biology," "Materials Problem Solving with Aberration-Corrected EM," and "Failure Analysis Applications of Microanalysis, Microscopy, Metallography, \& Fractography." Other physical science symposia will range from "Metallography and Microstructural Characterization of Metals" to "Microscopy and Characterization of Ceramics, Polymers, and Composites" to "Advances in Transmission Electron Microscopy and Spectroscopy of Energy-Related Materials."

The successful learning opportunities at previous M\&M meetings will be continued this year with pre-meeting and in-meeting courses taught by specialists in their fields. The topics of the nine premeeting short courses range from sample preparations for correlative microscopy for light and electron microscopy to practical considerations for quantitative image analysis for both biological and physical sciences. In-meeting courses will focus on the following topics: introduction to SEM imaging and X-ray compositional analysis, specimen preparation for biological microscopy, and nanomaterial microscopy/microanalysis. We also will showcase our educational opportunities for broader audiences: Project Micro, Microscopy in the Classroom, and It's a Family Affair.

The 2015 Pre-Meeting Congress, to be held all day Sunday, is "Measuring materials functionalities and dynamics in liquid and gaseous environment," organized by the MSA Electron Microscopy in Liquids and Gases (EMLG) focused interest group (FIG).

Of course M\&M 2015 will have the largest annual microscopy instrument exhibition in the world. Over 100 companies will display their latest equipment and services.

The social activities include the opening reception and the festivities at each day's poster and awards sessions. The latter events have become an afternoon tradition in the exhibition hall.

For a complete description of all the symposia, contributed sessions, educational opportunities, and the multiple award possibilities from the three organizing societies, please see the Call for Papers (distributed with the November Microscopy Today) or go to: http://www.microscopy.org/ MandM/2015/.

The Executive Program Committee and the large number of symposia organizers have created the palette for Microscopy \& Microanalysis 2015. This M\&M meeting promises to be the showcase meeting of the year for the smaller worlds around us. On behalf of MSA, MAS, and IMS, I invite you to participate. See you in Portland, Oregon!

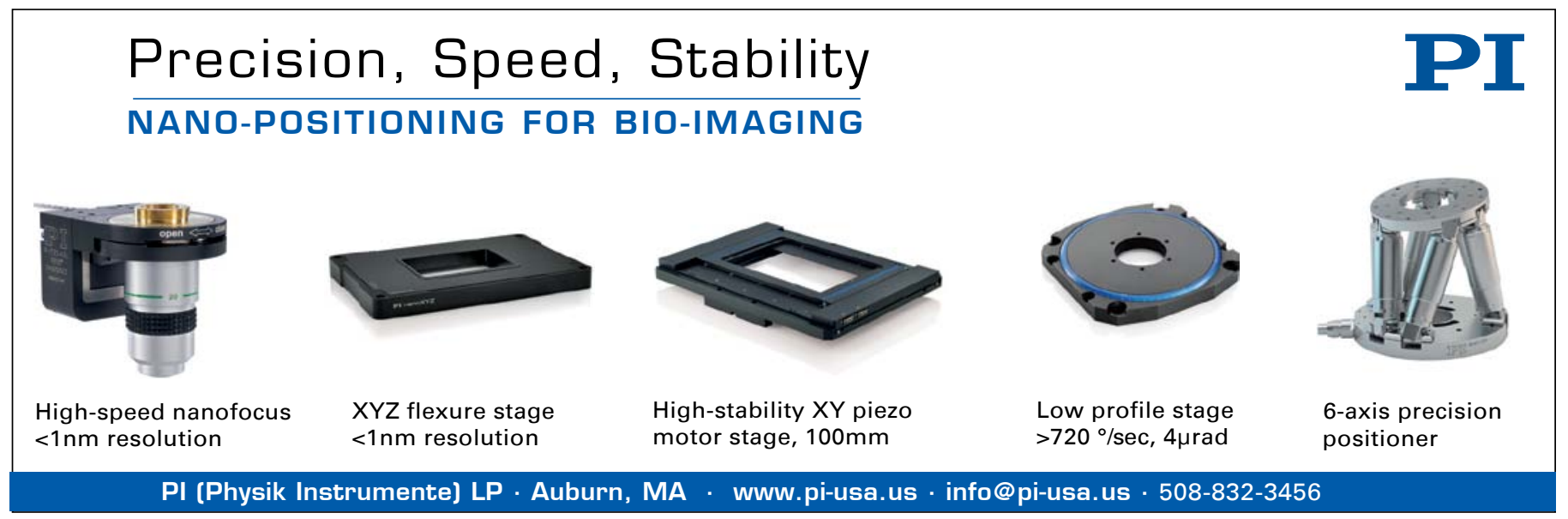




\section{June $7-12,2015$}

\section{LEHIGH}

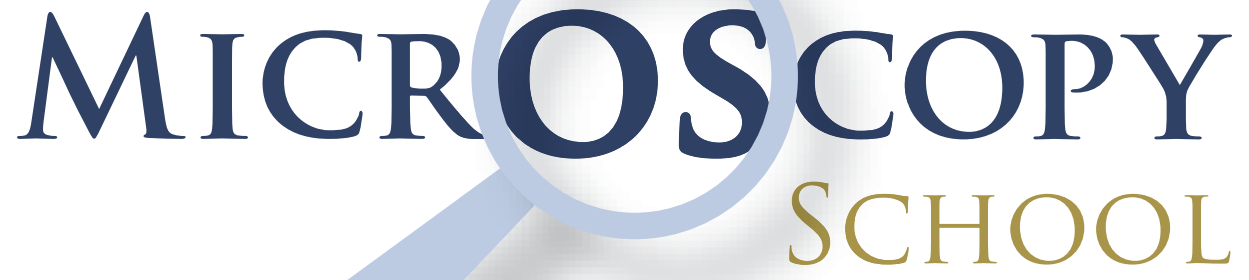

Lehigh University, Bethlehem, PA USA

\section{MAIN COURSES}

SCANNING ELECTRON MICROSCOPY AND X-RAY MICROANALYSIS

June 8-12

\section{SPECIALIZED COURSES}

FOCUSED ION BEAM (FIB): Instrumentation and Applications June 8-12

PROBLEM SOLVING:

Interpretation and Analysis of SEM/EDS/EBSD Data

June 8-12
INTRODUCTION TO SEM AND EDS FOR THE NEW OPERATOR June 7
QUANTITATIVE X-RAY

MICROANALYSIS:

Problem Solving using EDS and WDS Techniques June 8-12

SCANNING TRANSMISSION ELECTRON MICROSCOPY:

From Fundamentals to Advanced Applications June 8-12

For more information, contact:

Sharon Coe | 610.758.5133 | sharon.coe@lehigh.edu 